\title{
Androgen-producing bilateral large cortical adrenal adenomas associated with polycystic ovaries in a young female
}

\author{
D. Micić, S. Zorić, V. Popović, R. Janković, M. Jančić, R. Han, \\ D. Manojlović and J. Mićić
}

Institute of Endocrinology, Diabetes and Diseases of Metabolism, University Clinical Center, Belgrade, Yugoslavia

\begin{abstract}
Summary: An association of bilateral large adrenocortical androgen-producing adenomas with polycystic ovaries in a young female is presented. She developed mild hirsutism and secondary amenorrhoea at the age of.17, and was treated for 3 years with an anti-androgen (cyproterone acetate) and ethinyloestradiol. Routine follow-up at the age of 21 showed bilateral large adrenal tumours and polycystic ovaries, together with high serum testosterone and dehydroepiandrosterone sulphate values. Bilateral adrenalectomy was performed, which resulted in lowering of the elevated androgens, and large bilateral adrenocortical adenomas were confirmed histologically. Contrary to expectations, the polycystic appearance of the ovaries persisted after adrenalectomy.

This case supports the possible role of adrenal androgens in the pathogenesis of polycystic ovaries as well as the possibility of the persistence of polycystic ovaries without adrenal androgens once they have developed.
\end{abstract}

\section{Introduction}

Androgen-producing tumours must be considered as a possible cause of hirsutism in young females and should be excluded in each case. ${ }^{1}$ Evaluation for a possible adrenal carcinoma can generally be initiated with the size of the lesion used as the sole screening criterion. ${ }^{2}$ The prevalence of adrenal adenomas larger than $6 \mathrm{~cm}$ was estimated to be $0.025 \%{ }^{3}$

Although elevated circulating androgen levels have been found in women with the polycystic ovary syndrome it is not clear whether the excess androgen arises from adrenal or ovarian sources. ${ }^{4}$ The excessive production of adrenal androgens has been put forward as a prime factor in the aetiology of polycystic ovaries. ${ }^{5}$

We recently investigated a young female with hirsutism and found bilateral large androgenproducing adrenocortical adenomas associated with polycystic ovaries. Although bilateral adrenalectomy resulted in normalization of serum androgen levels, ultrasonographic appearance of polycystic ovaries continues to persist, 6 months after the adrenalectomy.

Correspondence: Assistant Professor Dr Dragan Micić, M.D., Institute of Endocrinology, Diabetes and Diseases of Metabolism, University Clinical Center, Dr Subotića 13, 11000 Belgrade, Yugoslavia

Accepted: 16 August 1991

\section{Case report}

A 22 year old female was admitted to our Institute for investigation of bilateral adrenal enlargement. She had menarche at the age of 12 . Periods were regular till the age of 17 . She then developed secondary amenorrhoea for 6 months, concomitantly with the appearance of hirsutism. At the age of $17 \frac{1}{2}$, endocrine evaluation verified normal testosterone and dehydroepiandrosterone sulphate (DHEA-S) values and elevated androstenedione with normal appearance of adrenals and ovaries on an ultrasound scan. A diagnosis of idiopathic hirsutism was established. Anti-androgen (cyproterone acetate) and ethinyloestradiol were administered cyclically for the next 3 years. There was no further progression of hirsutism during treatment and menstrual periods were regular. At the end of therapy she was again evaluated with ultrasound when large adrenals (left $5.5 \times 5.5 \mathrm{~cm}$, right $5.2 \times 5.5 \mathrm{~cm})$ were detected for the first time as well as polycystic ovaries (Figure 1). Hirsutism score at that time was ten ${ }^{6}$ and body mass index was $18.38 \mathrm{~kg} / \mathrm{m}^{2}$. The patient was mildly hypertensive $(140 / 100 \mathrm{mgHg})$, with masculine body build but without clitoromegaly.

Endocrine evaluation on the 7th day of the menstrual cycle, one month after stopping the anti-androgen therapy is shown in Table I. Car- 

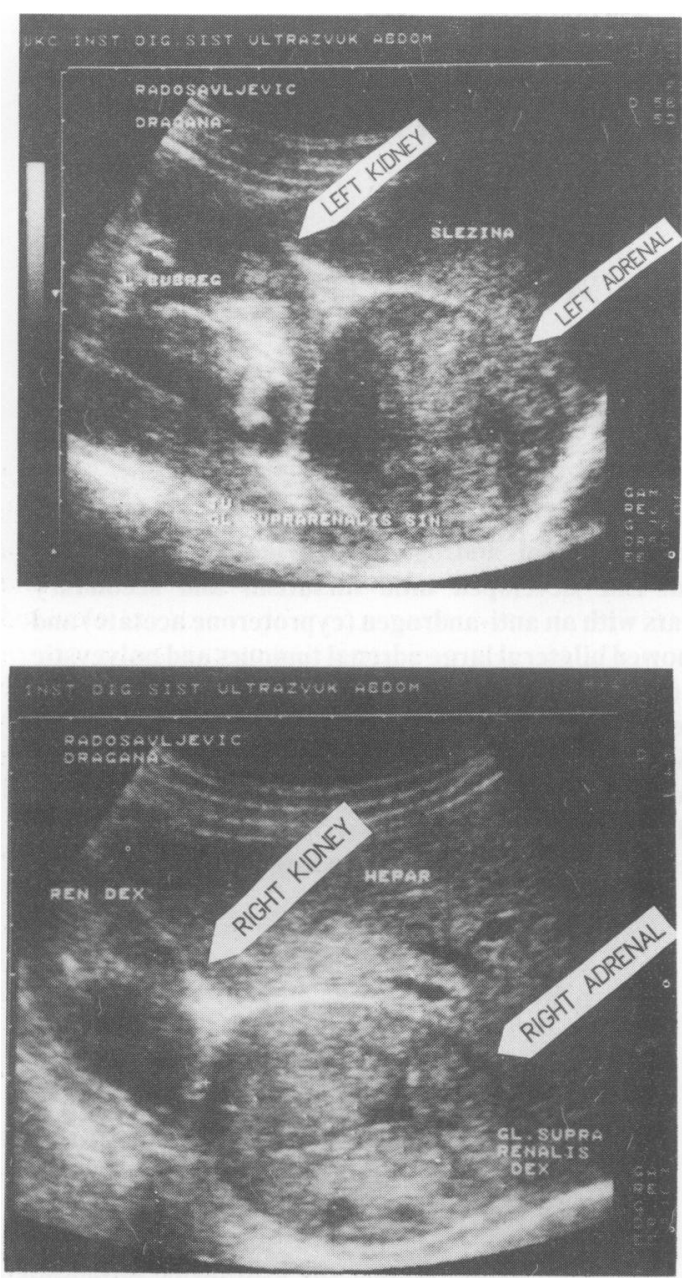

Figure 1 Large adrenal tumours on ultrasound examination. cinoembryonic antigen and feto protein were normal.

Cortisol response during insulin tolerance test

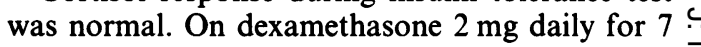
days there was significant suppression of plasma cortisol (568 to $21 \mathrm{nmol} / \mathrm{l}$ ) but not of plasma testosterone $(20.2$ to $15.2 \mathrm{nmol} / \mathrm{l})$.

There was a normal response of plasma $17-\frac{\bar{O}}{\bar{\omega}}$ hydroxyprogesterone to Synacthen stimulation $\vec{\nabla}$ (0.25 mg i.v.): $2.9,3.5,6.2,8.0$ and $2.3 \mathrm{nmol} / 1$ at 0 , $30,60,90$ and $120 \mathrm{~min}$, respectively.

Testosterone did not increase after human $\vec{\circ}$ chorionic gonadotrophin (hCG) stimulation (3000 IU daily, for 3 days): 16.0 vs $15.8 \mathrm{nmol} / \mathrm{l}$.

Hormone values obtained during selective venous catheterization of the adrenals and ovaries indicated the presence of elevated testosterone from both adrenals (Table II). It was concluded that the patient had autonomous non-suppressible androgen production from both adrenals.

Renal arteriography demonstrated bilateral $\underset{\cup}{\mathscr{0}}$ enlarged vascularized adrenal tumours with 0 suspected necrosis and cysts in the left adrenal. Both kidneys were displaced downwards. Nuclear $z$ magnetic resonance examination verified bilateral adrenal enlargement.

Since the adrenal tumours enlarged during follow-up over 3 months, we decided to perform $\bullet$ bilateral adrenalectomy. Regression of the hir sutism was observed post-operatively together with the resumption of periods, regular ovulation and normotension. Post-operative follow-up verified decreased androgen values (Table I). The patient is currently on replacement therapy (oral hydrocortisone, $20+5+5 \mathrm{mg}$, daily). The polycystic appearance of the ovaries persisted on postoperative ultrasound.

Gross examination after adrenalectomy revealed an enlarged right adrenal gland that measured

Table I Pre- and post-operative hormone values

\begin{tabular}{lcccc}
\hline & $\begin{array}{c}\text { Pre-operative } \\
\text { values }\end{array}$ & $\begin{array}{c}\text { 1 month } \\
\text { after } \\
\text { operation }\end{array}$ & $\begin{array}{c}6 \text { months } \\
\text { after } \\
\text { operation }\end{array}$ & $\begin{array}{c}\text { Reference } \\
\text { range }\end{array}$ \\
\hline Testosterone $(\mathrm{nmol} / \mathrm{l})$ & 14.4 & $<0.5$ & $<0.5$ & $0.7-3.5$ \\
Androstenedione $(\mathrm{nmol} / \mathrm{l})$ & 37.5 & 16.2 & 3.4 & $0.7-10.8$ \\
DHEA-S $(\mu \mathrm{mol} / \mathrm{l})$ & 14.0 & 6.8 & 0.66 & $3.2-9.8$ \\
Oestradiol $(\mathrm{pmol} / \mathrm{l})$ & 337 & 466 & 98 & $110-440$ \\
Progesterone $(\mathrm{nmol} / \mathrm{l})$ & 3.1 & 63.5 & 0.3 & $0.8-6.4$ \\
LH $(\mathrm{mIU} / \mathrm{ml})$ & 2.6 & 2.1 & 3.4 & $1.8-13.4$ \\
FSH $(\mathrm{mIU} / \mathrm{ml})$ & 6.0 & 2.0 & 7.1 & $3.0-12.0$ \\
Prolactin $(\mathrm{mU} / \mathrm{l})$ & 240 & 303 & 389 & $53-520$ \\
ACTH $(\mathrm{pg} / \mathrm{ml})$ & 35.0 & 42 & 20.0 & $1.0-50.6$ \\
Cortisol $(\mathrm{nmol} / \mathrm{l})$ & 432 & 370 & 689 & $138-690$ \\
17-OH progesterone $(\mathrm{nmol} / \mathrm{l})$ & 3.6 & 1.6 & 1.8 & $0.3-3.0$ \\
\hline
\end{tabular}

DHEA-S = dehydroepiandrosterone sulphate. 
Table II Hormone values during selective venous catheterization

\begin{tabular}{lccccc}
\hline Hormone & $\begin{array}{c}\text { Right } \\
\text { adrenal }\end{array}$ & $\begin{array}{c}\text { Left } \\
\text { adrenal }\end{array}$ & $\begin{array}{c}\text { Right } \\
\text { ovary }\end{array}$ & $\begin{array}{c}\text { Left } \\
\text { ovary }\end{array}$ & $\begin{array}{c}\text { Peripheral } \\
\text { sample }\end{array}$ \\
\hline Testosterone $(\mathrm{nmol} / \mathrm{l})$ & 33.2 & 17.8 & 16.3 & 14.4 & 10.8 \\
DHEA-S $(\mu \mathrm{mol} / \mathrm{l})$ & 38.3 & 30.0 & 18.6 & 23.5 & 15.7 \\
Androstenedione $(\mathrm{nmol} / \mathrm{l})$ & 66.0 & 55.1 & 52.6 & 41.1 & 40.1 \\
Cortisol $(\mathrm{nmol} / \mathrm{l})$ & 550.0 & 571.0 & 341.6 & 346.1 & 393.0 \\
Oestradiol $(\mathrm{pmol} / \mathrm{l})$ & - & - & 6,341 & 1,613 & - \\
\hline
\end{tabular}

$9 \times 7.5 \times 7 \mathrm{~cm}$ and weighed $140 \mathrm{~g}$, while the left adrenal weighed $120 \mathrm{~g}$, also with increased diameters $(9 \times 7 \times 6 \mathrm{~cm})$. It was possible to locate dark brown tumour tissue from the rest of the normal, compressed yellow cortex in both adrenals. There were multiple areas of necrosis and haemorrhage in both tumours.

The tumour histology showed eosinophilic compact cells showing well-marked nuclear pleomorphism. No mitoses were seen and there was no necrosis. There was no evidence of capsular or angioinvasion. Since the diagnosis of malignancy could not be entirely ruled out, pathohistology specimens were kindly reviewed by Professor I. Doniach in St Bartholomew's Hospital, London who confirmed large adrenal cortical adenomas. Nuclear pleomorphism was interpreted as a common finding in actively secreting endocrine hyperplasias and tumours, including functioning adrenal cortical adenomas.

\section{Discussion}

Endocrinologically active tumours of the adrenal cortex are rare in man. Publications about tumours forming sexual hormones are mostly descriptions of individual cases. ${ }^{7}$ Benign adrenocortical tumours are generally small $(<70 \mathrm{~g})$ and are usually single solitary nodules. ${ }^{8}$ In contrast, adrenal carcinomas are usually large when discovered and have often metastasized already at the time of diagnosis. High testosterone associated with a high DHEA-S suggests a tumour of adrenal origin and adrenal neoplasm is further suspected by means of non-suppressible adrenal hormone production in the presence of high doses of dexamethasone, as in our case. Although androgen/ cortisol ratios in adrenal veins were not convincingly higher than in peripheral samples we have definitive evidence for high testosterone of adrenal origin based on its low values after bilateral adrenalectomy. Postoperative serum testosterone measurement is a valuable marker for further follow-up of our patient.

The association between adrenocortical adenoma autonomously secreting androgens and polycystic ovaries may not be coincidental. It has been suggested that an excess of adrenal androgen in 21-hydroxylase deficiency, adrenal tumours, and Cushing's syndrome probably leads to elevated levels of oestrone and abnormal secretion of gonadotrophin, and thereby to the characteristic abnormalities in the ovaries. ${ }^{9-11}$ Very high, masculinizing plasma concentrations of androgens are capable of inducing the histopathologic changes of the polycystic ovary syndrome in the ovary, as indicated during the induction of virilization of transsexuals. ${ }^{12}$ Any disorder that causes an increase in ovarian androgen will cause excessive follicular atresia, which may be the initiating event in some cases of the polycystic ovary syndrome, and results in further androgen excess, compounding the initial problem. ${ }^{13}$ Polycystic ovaries were detected at the same time as androgen-producing adenomas in our patient and we expected that the reduction of adrenal androgen excess would lead to improvement of polycystic ovarian appearance. Since we have data for the persistence of polycystic ovaries together with low testosterone values after adrenalectomy, an analogy could be made with non-responders to dexamethasone among the patients with polycystic ovary disease in which a dominant ovarian abnormality, primary or secondary to the adrenal disorder was postulated. ${ }^{14}$ Alternatively, it is possible to speculate that two diseases coincided.

This case supports the hypothesis that, in at least some patients, polycystic ovary develops as a secondary change to the altered steroidal milieu, but may persist after surgical correction of adrenal hyperandrogenism due to perpetuation of the hyperandrogenic process with the ovary. ${ }^{15}$

\section{Acknowledgement}

This work was supported by a grant from the Republic Scientific Fund of Serbia. We thank Professor I. Doniach from St Bartholomew's Hospital, London for his help in re-evaluation of pathohistology specimens. 


\section{References}

1. Vierhapper, H., Nowotny, P., Krisch, K., Kletter, K. \& Waldhausl, W. Androgen-produziererendes Nebennierenadenom bei einer 18 juhrigen Patientin: diagnostik mittels gaschromatographischer Steroidanalyse, Histologie und postoperativer Verlauf. Wien Klin Wochenschr 1982, 94: 670-673.

2. Ross, N.S. \& Aron, D.C. Hormonal evaluation of the patient with an incidentally discovered adrenal mass. $N$ Engl $\mathrm{J} \mathrm{Med}$ 1990, 323: $1401-1405$.

3. Copeland, P.M. The incidentally discovered adrenal mass. Ann Intern Med 1983, 98: 940-945.

4. Wajchenberg, B.L., Achando, S.S., Okada, H. et al. Determination of the source(s) of androgen overproduction in hirsutism associated with polycystic ovary syndrome by simultaneous adrenal and ovarian venous catheterization. Comparison with the dexamethasone suppression test. J Clin Endocrinol Metab 1986, 636: 1204-1210.

5. Lobo, R.A. The role of the adrenal in polycystic ovary syndrome. Semin Reprod Endocrinol 1984, 2: 251-262.

6. Ferriman, D. \& Gallwey, J.D. Clinical assessment of body hair growth in women. J Clin Endocrinol Metab 1961, 21: $1440-1447$.

7. Gerl, H., Knappe, G., Neumann, P. \& Stahl, F. Androgenbildende Nebennierenrindentumoren. $Z$ Gesamte Inn Med 1979, 34: 618-623.

8. Slooten, H.V., Schaberg, A., Smeenk, D. \& Moolenaar, A. Morphologic characteristics of benign and malignant adrenocortical tumors. Cancer 1985, 55: 766-773.
9. McKenna, T.J. Pathogenesis and treatment of polycystic ovary. $N$ Engl J Med 1988, 318: 558-562.

10. Lobo, R.A. \& Goebelsmann, U. Adult manifestation of congenital adrenal hyperplasia due to incomplete 21hydroxylase deficiency mimicking polycystic ovarian disease. Am J Obstet Gynecol 1980, 138: 720-726.

11. Kase, N., Kowal, J., Perloff, W. \& Soffer, L.J. In vitro production of androgens by a virilizing adrenal adenoma and associated polycystic ovaries. Acta Endocrinol 1963, 44: 15-19.

12. Futterweit, W. \& Deligdisch, I. Histopathological effects of exogenously administered testosterone in 19 female to male transexuals. J Clin Endocrinol Metab 1986, 62: 16-21.

13. Barnes, R. \& Rosenfield, R.L. The polycystic ovary syndrome: pathogenesis and treatment. Ann Intern Med 1989, 110: $386-399$.

14. Loughlin, T., Cunningham, S., Moore, A., Culliton, M., Smyth, P.P.A. \& McKenna, T.J. Adrenal abnormalities in polycystic ovary syndrome. J Clin Endocrinol Metab 1986, 62: $142-147$.

15. Barbieri, R.L., Smith, S. \& Ryan, K.J. The role of hyperinsulinemia in the pathogenesis of ovarian hyperandrogenism. Fert Steril 1988, 50: 197-212. 